\title{
PRODUÇÃO DE QUITOSANA A PARTIR DA QUITINA EXTRAíDA DE RESÍDUOS DE CRUSTÁCEOS
}

\author{
Caroline de Souza Fontes ${ }^{1}$ \\ Talita Cattem Mainetti Vargas ${ }^{2}$ \\ Arlan Figueiredo de Carvalho ${ }^{3}$ \\ Lorena Montenegro Silva ${ }^{4}$ \\ Blenda Vargas Cade ${ }^{5}$ \\ Fernanda Machado Carrai Medeiros ${ }^{6}$ \\ Otoniel de Aquino Azevedo ${ }^{7}$ \\ Adilson Vidal Costa ${ }^{8}$ \\ Vagner Tebaldi de Queiroz $^{9}$
}

Resumo: A atividade pesqueira brasileira gera um PIB de $R \$ 5$ bilhõese mobiliza 800 mil profissionais. Em função desta atividade econômica, o descarte de resíduos de crustáceos sem nenhum tratamento tem se tornado um problema ambiental, uma proposta para minimiza-lo é a utilização destes resíduos para a obtenção de matéria prima de interesse industrial. Sendo assim, foi avaliado o efeito da concentração do $\mathrm{NaOH}$ no processo de obtenção da quitosana. Com base na utilização de materiais comuns de laboratório, a obtenção da quitosana foi realizada a partir da algumas etapas, como a desacetilação da quitina. Esta proposta demonstrou-se eficiente uma vez que o aumento no teor de $\mathrm{NaOH}$ promoveu um aumento no rendimento na produção da quitosana. Acredita-se que este trabalho venha a contribuir com a redução de resíduos de crustáceos, visto que o interesse industrial pela quitosana vem aumentando devido as suas propriedades bacteriostáticas, fungistática e cicatrizantes.

Palavras-chave: Resíduos de crustáceos; Quitina; Quitosana.

\footnotetext{
${ }^{1}$ Graduada/Centro Universitário São Camilo, Brasil. E-mail:. carolinefontes17@gmail.com.

2 Graduada/Centro Universitário São Camilo, Brasil. E-mail: talitacattem@gmail.com.

${ }^{3}$ Engenharia Química/ Universidade Federal do Espírito Santo, Brasil. E-mail: arlanfigueiredo@hotmail.com.

${ }^{4}$ Química Licenciatura/ Universidade Federal do Espírito Santo, Brasil. E-mail: Iorena-mn@hotmail.com.

${ }^{5}$ Graduada/Centro Universitário São Camilo, Brasil. E-mail: blendavargasc@hotmail.com.

${ }^{6}$ Graduada/Centro Universitário São Camilo, Brasil. E-mail: fmachadocarrari@yahoo.com.br.

7 Professor/Centro Universitário São Camilo, Brasil. E-mail: otoazevedo@gmail.com.

8 Pesquisador/Universidade Federal do Espírito Santo, Brasil. E-mail: avcosta@hotmail.com.

${ }^{9}$ Orientador/Universidade Federal do Espírito Santo, Brasil. E-mail: vagnertq@gmail.com.
} 